\title{
Knowledge and Practice of Pregnant Iraqi Women about COVID-19 Preventive Measures
}

\author{
Thikra N. Abdulla ${ }^{1}$, Weqar Akram², Taghreed MardanAbullah ${ }^{3}$ \\ ${ }^{1}$ Ass. Pro. Department of Obs. \& Gyn., Al-Kindy College of Medicine, Baghdad University, ${ }^{2}$ Lecturer, Department \\ of Obs. \& Gyn., Al-Kindy College of Medicine, Baghdad University, ${ }^{3}$ Specialist Obstetrics \& Gyn., Abugraib \\ General Hospital
}

\begin{abstract}
Background: Pregnant women with SARS-CoV-2 infection must be identified and treated early because they are a group susceptible to higher risk as more cases of infection appear, the timely diagnosis will allow us to select which patients merit maternal surveillance. Much closer fetal and/or timely hospital admission with an immediate impact on emergency clinical practice
\end{abstract}

Objective: To assess the knowledge and practice of pregnant Iraqi women about COVID-19 preventive measures.

Patients and Method: A cross sectional study conducted at the Private clinics for Gynecology and Obstetrics in Baghdad/Iraq for two months, from 1 of May 2020 to the end of Jun 2020. The study sample is 400 pregnant women that are attending private clinics for antenatal care, studying their knowledge about COVID-19 infection and their approach.

Results: The Knowledge score level were found Inadequate in (72\%) of the participant and adequate in (28\%), the main source of information about the COVID-19 prevention in multiple answers question was $\mathrm{TV}$, which presented in $338(84.5 \%)$, then 234 (58.5\%) from family and friends, $229(57.25 \%)$ and 103 $(25.75 \%)$ mentioned that their information from HCWs. $2 / 3^{\text {rd }}$ of the participants were presented with poor practice $(67.25 \%)$ while less than $1 / 3^{\text {rd }}(32.75 \%)$ with good practice.

Conclusion: Knowledge score level were found Inadequate in (72\%) of the participant and $2 / 3^{\text {rd }}$ of the participants were presented with poor practice $(67.25 \%)$ while less than $1 / 3^{\text {rd }}(32.75 \%)$ with good practice.

Keyword: COVID-19, Knowledge, Practice, Pregnant, prevention, infection.

\section{Introduction}

On December 2019, an outbreak of a respiratory syndrome was emerged in Wuhan in China that alerted severe acute disease (SARS) caused by a new Coronavirus (SARS-CoV-2), on March 2020, the WHO

\section{Corresponding Author:}

\section{Dr. Thikra Najim Abdulla}

Ass. Pro. Department of Obs. \& Gyn., Al-Kindy

College of Medicine, Baghdad University

e-mail:drthikra@yahoo.com

Contact Number: +9647901429658 declared the disease as pandemic, To date, SARSCoV-2 infected millions of peoples and causing several thousands of death and it still progressing in many countries. $^{(1)}$

The risk factors that are associated with both SARSas higher mortality are age over 65 years, obesity, diabetes, hypertension, The hypothesis related to these comorbidities is the over expression of ACE 2 receptors, which could facilitate the entry of the virus into the pneumocyte, where it would replicate exponentially and attract to leukocytes and macrophages that would produce pro-inflammatory cytokines that would give rise to SARS. So far, the evidence is inconclusive as 
to whether pregnancy confers greater susceptibility to serious complications and vertical transmission of mother-fetus. ${ }^{(2)}$ However, the data are very limited by the low incidence of the disease, so only in 32 cases of pregnant women with SARS-CoV-2, 7 (22\%) were asymptomatic, $2(6 \%)$ were admitted to the intensive care unit, 15(47\%) developed preterm delivery, 1(3\%) developed stillbirth, and there was a neonatal death. ${ }^{(3)}$

The infection by the new Coronavirus SARS-CoV-2, is an unprecedented pandemic and therefore a public health emergency, highly contagious and producing severe acute respiratory syndrome (SARS). The incubation period is 3-7 days, but can vary between 1-14 days. ${ }^{(4)}$ Fever is the most frequent symptom contributed for $88.7 \%$, followed by cough in $67.8 \%$ of cases, myalgia, sputum dyspnea, sore throat, headache, and diarrhea in a rate ranged $3.8 \%$ to $38.1 \%$, Complications such as pneumonia with infiltrates bilateral, syndrome of distress respiratory acute, arrhythmia, acute kidney injury, cardiac abnormalities and liver damage are common in symptomatic patients with comorbidities. ${ }^{(5)}$

The transmission of diseases is primarily, by direct person-to-person contact transmission between infected and non-infected individuals. ${ }^{(6)}$

Pregnant women do not appear to be more susceptible to contracting the infection, nor to presenting serious complications, but the existing data are limited.

In any case, pregnant women with SARS-CoV-2 infection must be identified and treated early because they are a group susceptible to higher risk as more cases of infection appear, the timely diagnosis will allow us to select which patients merit maternal surveillance -Much closer fetal and/or timely hospital admission with an immediate impact on emergency clinical practice. ${ }^{(7)}$

There is little evidence about the possibility of mother-fetus transmission. As the pregnant patient is classified as a vulnerable group there is no solid evidence of a higher risk of infection or complications, all patients suspected having SARS-CoV-2 infection should be referred to a COVID referral unit to perform aSARSCoV-2 diagnostic molecular test. Timely referral of all pregnant patients suspected of SARS-CoV-2 infection to specialized COVID units with obstetric care are recommended. ${ }^{(8)}$

On the other hand, infected pregnant women with decreased fetal movements, vaginal bleeding, severe headache that does not go away with pain reliever, tinnitus, rupture of membranes, sudden and significant edema of the lower extremities with high suspicious symptoms or a serious symptom, it is required to transfer by ambulance to the nearest COVID referral center. ${ }^{(9)}$

The patient must wear a surgical mask at all times and must be sent to the special isolation zone established for each hospital unit. Avoid entrance of the companion who must wait outside the building or in the waiting room. The most important thing is to assess whether the patient has serious features that require an early intervention. For this reason, the first thing to do is to assess whether the patient is serious or not and then assess for the diagnosis of COVID-19 infection. ${ }^{(10)}$

Treatment of COVID-19 during pregnancy still under debate; there are more than 49 randomized clinical trials in the world in search of a cure for SARSCoV-2 infection. However, of the proposed treatments, their safety, effectiveness, dose, stage of disease to be administered, and safety during pregnancy are still unclear. Treatments such as Hydroxychloroquine are safe in pregnancy and appear to be promising, however, information on its efficacy and safety, as well as its dose and stage of disease to which it should be administered comes from non-randomized studies and not blind. ${ }^{(11)}$ Every pregnant woman should go for obstetric reassessment in a specialized referral hospital. Fetal viability in all trimesters and fetal weight will be added by percentile calculation of weight for gestational age and Doppler (in cases less than 10th percentile of weight) in third trimester. ${ }^{(12)}$

There is evidence that post-infection patients remain positive for SARSCoV-2 infection for 7 days after the resolution of the clinical picture.

Patients with a negative test should rule out influenza or other infectious pathologies. These patients should be managed according to their symptoms or obstetric pathology of preference in hospitalization area outside of isolation and out of risk of infection with COVID-19. (13)

Clinically, pregnant women during her hospital stay must be kept in isolation. It is not contemplated accompaniment by family. The patient should be monitored for pulse-oximetry and vital-signs regularly at least 4 times a day and fetal heart rate monitoring 1 time a day. Terminating a pregnancy in a patient with SARS-CoV-2, in stable patients there is no indication to interrupt the pregnancy. Whenever possible. The decision 
to terminate the pregnancy in stable patients will be done under multidisciplinary consensus due to unfavorable evolution according tomaternal deterioration. ${ }^{(14)}$

Maternal and fetal well-being should be monitored. In the case of fetal surveillance,conducting continuous electronic monitoring of fetal heart rate for 20 minutes, can help us identify changes in fetal physiology reflected in normal patterns and abnormal of it. ${ }^{(15)}$ Postnatally, it is unknown if infection with SARS-COV2 can be pass through breast milk and there is a little evidence about SARS-CoV in mother's milk. Recent studies documented negative evidence about the transmission through breast milk and all samples were reported negative. Currently experience is limited and it is a subject under investigation. ${ }^{(16)}$

Aim of the Study: To assess the knowledge and practice of pregnant Iraqi women about COVID-19 preventive measures.

\section{Patients and Method}

A cross sectional study conducted at the Private clinics for Gynecology and Obstetrics in Baghdad/Iraq for two months, from 1 of May 2020 to the end of Jun 2020. The study sample is 400 pregnant women that are attending private clinics for antenatal care, studying their knowledge about COVID-19 infection and their approach.
A detailed questioner from each patient after taking her consent verbally for participation, it should include the following: patient educational state and residence and home conditions.

The questionnaire included: information about the virus, did she hear about it, form where she heard, does she believe about it, is the virus the same to common flu, what causes this disease, transmission mode and duration of symptoms since transmission, how patient suspect infection, how serious she thinks the disease, could it be asymptomatic, who can get the disease, does she think that pregnant women are liable to get it more than general population, does she think it is more severe during pregnancy, how does it spread, what can kill the virus, what are the protective personal approaches, does she believe and practice the following: social distance, hand washing, wearing mask, not contact with suspected or sick people, isolation if suspected, cleaning surfaces, using antiseptics, consult a doctor if suspect symptoms.

Statistical Analysis: A pretested and validated questionnaire was used to collect the data. Data analysis was done using SPSS version 23

\section{Results}

As shown in figure 1 the main age group were between (20-29) years old as (50.5\%) of the participants were found in this group, $(23.75 \%)$ was in age group $(30-39) .19 \%)$ in $<20$ years and $(6.75 \%)$ in $\geq 40$ years.

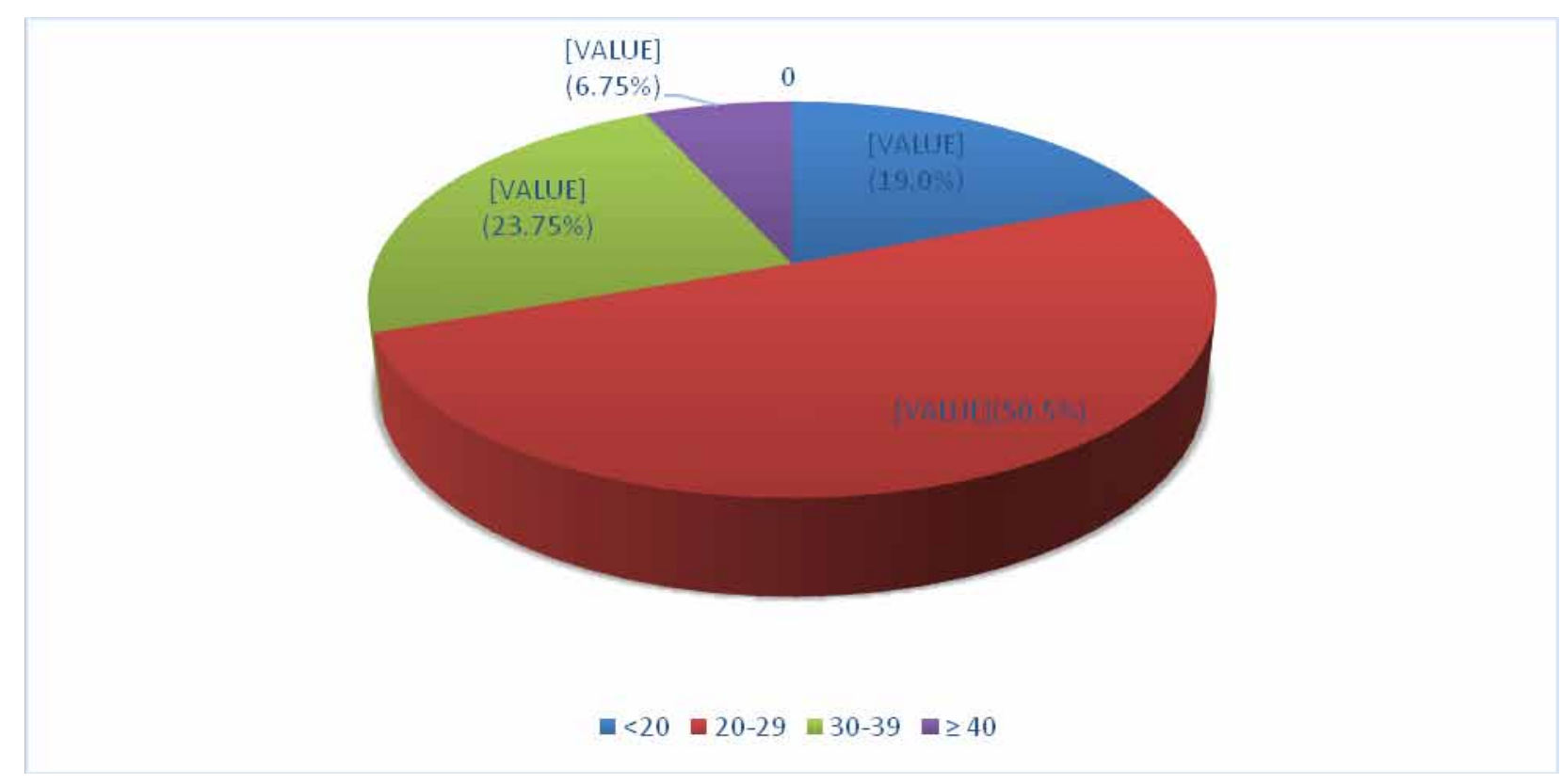

Fig 1: Age distribution of the studied group 
Table 1 show that the Knowledge score level were found Inadequate in $(72 \%)$ of the participant and adequate in $(28 \%)$

Table 1: Knowledge score level

\begin{tabular}{|l|l|c|c|}
\hline \multicolumn{2}{|l|}{ Variable } & N & \% \\
\hline $\begin{array}{l}\text { Participants' knowledge } \\
\text { level about COVID-19 }\end{array}$ & Inadequate & 288 & 72.0 \\
\cline { 2 - 4 } & Adequate & 112 & 28.0 \\
\hline Total & $\mathbf{4 0 0}$ & $\mathbf{1 0 0 . 0}$ \\
\hline
\end{tabular}

The main source of information about the COVID-19 prevention in multiple answers question was social media, which presented in $338(84.5 \%)$, then 234 (58.5\%) from family and friends, TV in 229 (57.25\%) and $103(25.75 \%)$ mentioned that their information from HCWs (table 2).

Table 2: Sources of their information

\begin{tabular}{|l|c|c|}
\hline Source of information* & No & \% \\
\hline Social media & 338 & 84.5 \\
\hline Family and Friends & 234 & 58.5 \\
\hline TV & 229 & 57.25 \\
\hline HCWs & 103 & 25.75 \\
\hline
\end{tabular}

*Multiple Responses

$384(96 \%)$ of the pregnant women heard about corona virus at the time of the study while $16(4 \%)$ don't heard about it (fig 2).

\section{FIGURE 3: CLINICAL SEVERITY OF POISONING}

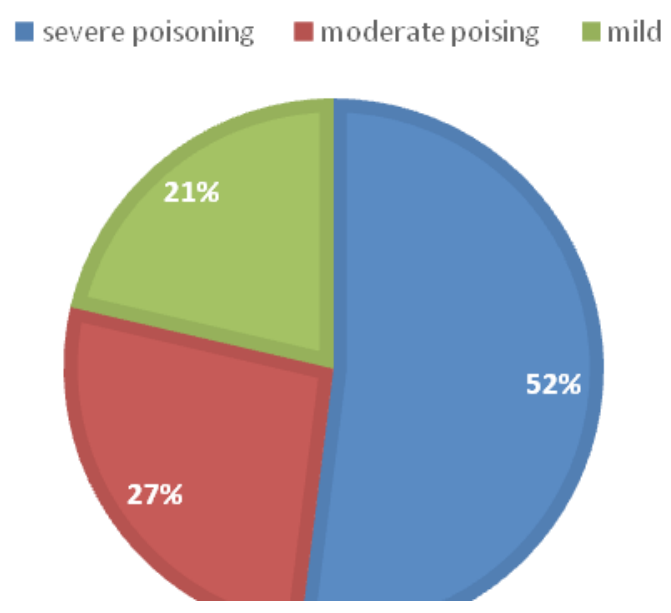

Fig 2: Heard about Novel coronavirus

Table 3, mentioned that about $2 / 3^{\text {rd }}$ of the participants were presented with poor practice $(67.25 \%)$ while less than $1 / 3^{\text {rd }}(32.75 \%)$ with good practice

\section{Table 3: Practice level about prevention of COVID-19 infection}

\begin{tabular}{|l|l|c|c|}
\hline \multicolumn{2}{|l|}{ Variable } & N. & \% \\
\hline $\begin{array}{l}\text { Participants' practice level about } \\
\text { prevention of COVID-19 }\end{array}$ & Poor & 269 & 67.25 \\
\cline { 2 - 4 } & Good & 131 & 32.75 \\
\hline \multicolumn{2}{|l}{ Total } & $\mathbf{4 0 0}$ & $\mathbf{1 0 0 . 0}$ \\
\hline
\end{tabular}

For the participant practice response for preventing COVID-19 show that 73 (18.25.0\%) choose the washing hands frequently as major preventive way, 59 (14.75\%) said that a distance for 2 meters and more between the people can prevent the infection with disease. 67 (16.75\%) choose do not touch eye, nose and mouth with hands, 123 (30.75\%) choose wearing mask was the common way to prevent the infection, and 78 (19.5\%) mentioned staying home was the way to prevent infection with the disease (fig 3). 




Fig 3: Response of participants among practice of preventing COVID-19

\section{Discussion}

The current study provide a shed light about the level of knowledge and practice among preventive measurement of COVID-19 infection in pregnant Iraqi women. The current study show that the level of knowledge were inadequate in about $3 / 4^{\text {th }}$ of the participants, which is not in agreement with Nawafor $\mathrm{J}$ et al, ${ }^{(17)}$ study carried in Nigeria, revealed that $(60.9 \%)$ of the pregnant women were presented with adequate knowledge. This may be due to their people trusted to the news when heard from their government that is opposite to our peoples.

The main source of information of the participants in the present study about the COVID-19 prevention in multiple answers question was TV, then family and friends, lastly was from HCWs. Which is in agreement with Bekele D et al, ${ }^{(18)}$ study when they revealed that social media were the main source of information for the participants, then TV. Moreover,Olapegba et al., found that media was the main source of their information. ${ }^{(19)}$

The majorities of the respondents were heard about the COVID-19 at the time of the study, this is more than that found in a study carried by Ikhaq A et al, in Pakistan found $90 \%$ of the respondents were heard about the disease. ${ }^{(19)}$ GeoPoll et al in their survey carried on three African countries revealed that more than $(94 \%)$ of the participants were heard about the COVID-19. ${ }^{(20)}$

In the present study participant said that the most common way to prevent the infection were by do not touch eye, noseand mouth with hands (30.75\%), then (19.5\%) mentioned staying home. This is not in agreement with Azlan A et al, study carried in Malaysia when found that proper washing hand is the common way to prevent infection with COVID-19 then avoiding crowded area. And the least common was those choosing wearing of face mask. ${ }^{(21)}$ Poor practice were common in the present study while Al-Hanawi M et al in their study done in Saudi Arabia revealed good practice score with good knowledge score in the studied group. ${ }^{(22)}$

\section{Conclusion}

Knowledge score level were found Inadequate in $(72 \%)$ of the participant and $2 / 3^{\text {rd }}$ of the participants were presented with poor practice $(67.25 \%)$ while less than $1 / 3^{\text {rd }}(32.75 \%)$ with good practice.

\section{No conflicts of interest}


Source of Funding: Self

Ethical Clearance: Was taken from the scientific committee of the Iraqi Ministry of health

\section{References}

1. Huang $\mathrm{C}$, Wang $\mathrm{Y}$, Li X, Ren L, Zhao J, Hu Y, Zhang L, Fan G, Xu J, Gu X, Cheng Z. Clinical features of patients infected with 2019 novel coronavirus in Wuhan, China. The lancet. $2020 \mathrm{Feb}$ 15;395(10223):497-506.

2. Rebello CJ, Kirwan JP, Greenway FL. Obesity, the most common comorbidity in SARS-CoV-2: is leptin the link?. International Journal of Obesity. $2020 \mathrm{Jul}$ 9:1-8.

3. Yan J, Guo J, Fan C, Juan J, Yu X, Li J, et al. Coronavirus disease 2019 (COVID-19) in pregnant women: A report based on 116 cases. American journal of obstetrics and gynecology. 2020 Apr 23.

4. Franjić S. COVID-19 in Croatia. Asploro Journal of Biomedical and Clinical Case Reports. 2020;3(2): 106 .

5. El-Baz LM, Elwakeel KZ, Elgarahy AM. COVID-19 from mysterious enemy to an environmental detection process: a critical review. Innovative Infrastructure Solutions. 2020 Dec; 5(3):1-3.

6. Al-Balas M, Al-Balas HI, Al-Balas H. Surgery during the COVID-19 pandemic: a comprehensive overview and perioperative care. The American Journal of Surgery. 2020 Jun 1; 219(6):903-6.

7. Ellington S, Strid P, Tong VT, Woodworth K, Galang RR, Zambrano LD, et al. Characteristics of women of reproductive age with laboratoryconfirmed SARS-CoV-2 infection by pregnancy status-United States, January 22-June 7, 2020. Morbidity and Mortality Weekly Report. 2020 Jun 26; 69(25):769.

8. Karimi-Zarchi M, Neamatzadeh H, Dastgheib SA, Abbasi H, Mirjalili SR, Behforouz A, et al. Vertical transmission of coronavirus disease 19 (COVID-19) from infected pregnant mothers to neonates: a review. Fetal and pediatric pathology. 2020 Apr 1:1-5.

9. Al-kuraishy HM, Al-Maiahy TJ, Al-Gareeb AI, Musa RA, Ali ZH. COVID-19 pneumonia in an Iraqi pregnant woman with preterm delivery. Asian Pacific Journal of Reproduction. 2020 May
1;9(3):156.

10. Desborough J, Hall SL, de Toca L, Davis S, Roberts L, Kelaher C, Kidd M. Australia's national COVID-19 primary care response. Med J Aust. 2020 Apr 29;1.

11. Favilli A, MatteiGentili M, Raspa F, Giardina I, Parazzini F, Vitagliano A, et al. Effectiveness and safety of available treatments for COVID-19 during pregnancy: a critical review. The Journal of Maternal-Fetal \& Neonatal Medicine. 2020 Jun 5:1-4.

12. NOVAC MV, Iliescu DG, TUDORACHE S, MANOLEA M, MEETESCU RE, VRABIE S, Novac MB, Alexandru DO, DIJMARESCU L. Ultrasound Evaluation of Fetal Biometry and Doppler Parameters in the Third Trimester of Pregnancy Suspected of Intrauterine Growth Restriction. Current Health Sciences Journal. 2018 Jan;44(1):23.

13. Centers for Disease Control and Prevention. interim clinical guidance for management of patients with confirmed 2019 novel coronavirus (2019-nCoV) Infection. Updated February. 2020;12.

14. Wu YT, Li C, Zhang CJ, Huang HF. Is termination of early pregnancy indicated in women with COVID-19?. European Journal of Obstetrics and Gynecology and Reproductive Biology. 2020 May 20.

15. Marim F, Karadogan D, Eyuboglu TS, Emiralioglu N, Gurkan CG, Toreyin ZN, et al. Lessons Learned so Far from the Pandemic: A Review on Pregnants and Neonates with COVID-19. The Eurasian Journal of Medicine. 2020 Jun;52(2):202.

16. Lackey KA, Pace RM, Williams JE, Bode L, Donovan SM, Järvinen KM, et al. SARS-CoV-2 and human milk: What is the evidence? Maternal \& Child Nutrition. 2020 Apr 11:e13032.

17. Nwafor JI, Aniukwu JK, Anozie BO, Ikeotuonye AC. Knowledge and practice of preventive measures against COVID-19 infection among pregnant women in a low-resource African setting. medRxiv. 2020 Jan 1.

18. Bekele D, Tolossa T, Tsegaye R, Teshome W. The knowledge and practice towards COVID-19 pandemic prevention among residents of Ethiopia. An online cross-sectional study. BioRxiv. 2020 Jan 1.

19. Ikhlaq A, Hunniya BE, Riaz IB, Ijaz F. Awareness 
and Attitude of Undergraduate Medical Students towards 2019-novel Corona virus. Pakistan Journal of Medical Sciences. 2020 May;36(COVID19S4):S32.

20. GeoPoll. A study of the knowledge and perceptions of coronavirus (COVID-19) in South Africa, Kenya, and Nigeria. 2020. Available at: https:// reliefweb.int/report/world/coronavirus-africastudy-knowledge-and-perceptions-coronaviruscovid-19-south-africa. Accessed on 23/8/2020
21. Azlan AA, Hamzah MR, Sern TJ, Ayub SH, Mohamad E. Public knowledge, attitudes and practices towards COVID-19: A crosssectional study in Malaysia. Plos one. 2020 May 21;15(5):e0233668.

22. Al-Hanawi MK, Angawi K, Alshareef N, Qattan AM, Helmy HZ, Abudawood Y, et al. Knowledge, Attitude and Practice Toward COVID-19 Among the Public in the Kingdom of Saudi Arabia: A Cross-Sectional Study. Frontiers in Public Health. 2020;8. 